\title{
Tumors of the Acromion Process-A Pictorial Review
}

\author{
$\begin{array}{llll}\text { S.L. Boo } & 10 & \text { A. Saad } & \text { Z. Khan } \\ & \text { A. M. Davies } & \text { S. L. James } & \text { R. Botchu }\end{array}$ \\ ${ }^{1}$ Department of Musculoskeletal Radiology, The Royal Orthopaedic \\ Hospital NHS Foundation Trust, Birmingham, United Kingdom \\ 2 Department of Orthopedic Oncology, The Royal Orthopaedic \\ Hospital NHS Foundation Trust, Birmingham, United Kingdom

\begin{abstract}
Address for correspondence Rajesh Botchu, Department of Musculoskeletal Radiology, The Royal Orthopaedic Hospital NHS Foundation Trust, Bristol Road South, Northfield, Birmingham B31 2AP, United Kingdom (e-mail: drbrajesh@yahoo.com).
\end{abstract}

Indian J Radiol Imaging 2021;31:850-857.
Abstract
Introduction Acromion is essential for stabilizing the shoulder complex. Tumors of the acromion are rare. We report the largest series of acromion tumor and tumor-like lesion.
Materials and Methods A retrospective review of the oncology and radiology
Keywords database within our tertiary center for orthopaedic oncology was performed to identify
- acromion all tumors of the acromion over the past 30 years and imaging was reviewed.
- tumors Results We identified a total of 31 lesions arising in the acromion and chondrosar-
coma was the commonest.
- process
Conclusion One needs to be aware of tumor and tumor-like lesions of acromion.

\section{Introduction}

The acromion process is an anatomical structure that is essential in stabilizing the shoulder complex and forms attachments to many important muscles of the shoulder joint. Tumors arising from the acromion process are considered rare and the literature regarding their clinicopathological characteristics, radiological findings, and management is scarce. Due to this, diagnosis is often delayed, resulting in poor patient outcomes. ${ }^{1}$

Radiographs, computed tomography (CT), and magnetic resonance imaging (MRI) all play a major role in the characterization of these lesions. This study reports the largest case series of isolated tumors of the acromion, and provides a pictorial review to illustrate imaging findings of tumors and tumor-like lesions at this site.

\section{Methodology}

A retrospective review of the oncology and radiology database within our tertiary center for orthopaedic oncology was performed to identify all tumors of the acromion over the past 30 years. All available imaging were reviewed by a musculoskeletal radiologist with more than 8 years' experience. Patient demographics including age, sex, and tumor type were recorded.

\section{Results}

We identified a total of 31 lesions arising in the acromion ( - Table 1 ). The average age was 52 years (range: 12-84 years). There was a female predominance with a female-tomale ratio of 1.6:1 ( 19 females and 12 males). The majority of the lesions identified within our cohort were malignant constituting $75 \%(n=23)$ of all cases. Benign tumors were found in $19 \%(n=6)$ and nonneoplastic lesions formed $6 \%$ of all cases $(n=2)$ (-Table 2 ). There was a mixture of benign and malignant lesions in different age groups (especially $>30$ and $<30$ years).

The most common isolated malignant tumor identified was chondrosarcoma $(n=7)$. This was closely followed by plasmacytoma in six cases. All other malignant tumors are published online

November 1, 2021
DOI https://doi.org/ 10.1055/s-0041-1735916. ISSN 0971-3026.

\footnotetext{
(C) 2021. Indian Radiological Association. All rights reserved.

This is an open access article published by Thieme under the terms of the Creative Commons Attribution-NonDerivative-NonCommercial-License, permitting copying and reproduction so long as the original work is given appropriate credit. Contents may not be used for commercial purposes, or adapted, remixed, transformed or built upon. (https://creativecommons.org/ licenses/by-nc-nd/4.0/)

Thieme Medical and Scientific Publishers Pvt. Ltd., A-12, 2nd Floor, Sector 2, Noida-201301 UP, India
} 
Table 1 Acromial tumors population demographics

\begin{tabular}{|c|c|c|c|c|}
\hline Patient & Gender & Age at diagnosis (y) & Tumor type & Diagnosis \\
\hline 1 & $\mathrm{M}$ & 12 & Benign & Fibrous dysplasia \\
\hline 2 & $M$ & 16 & Benign & Osteochondroma \\
\hline 3 & $\mathrm{~F}$ & 22 & Malignant & Chondrosarcoma \\
\hline 4 & $\mathrm{~F}$ & 29 & Benign & Eosinophilic granuloma \\
\hline 5 & $\mathrm{M}$ & 29 & Malignant & Chondrosarcoma \\
\hline 6 & $\mathrm{~F}$ & 30 & Benign & Osteochondroma \\
\hline 7 & $\mathrm{M}$ & 38 & Malignant & Metastasis \\
\hline 8 & $\mathrm{M}$ & 38 & Malignant & Plasmacytoma \\
\hline 9 & $\mathrm{~F}$ & 39 & Malignant & Chondrosarcoma \\
\hline 10 & $\mathrm{~F}$ & 41 & Malignant & Chondrosarcoma \\
\hline 11 & $\mathrm{M}$ & 43 & Benign & Osteochondroma \\
\hline 12 & $\mathrm{~F}$ & 46 & Malignant & Metastasis \\
\hline 13 & $\mathrm{~F}$ & 49 & Malignant & Lymphoma \\
\hline 14 & $\mathrm{~F}$ & 51 & Malignant & Chondrosarcoma \\
\hline 15 & $\mathrm{M}$ & 53 & Malignant & Lymphoma \\
\hline 16 & $M$ & 54 & Benign & Chondroblastoma \\
\hline 17 & $\mathrm{~F}$ & 59 & Malignant & Multiple myeloma \\
\hline 18 & $M$ & 61 & Malignant & Chondrosarcoma \\
\hline 19 & $\mathrm{~F}$ & 62 & Malignant & Metastasis \\
\hline 20 & $\mathrm{~F}$ & 66 & Malignant & Metastasis \\
\hline 21 & $\mathrm{~F}$ & 66 & Benign & Infection \\
\hline 22 & $\mathrm{~F}$ & 66 & Malignant & Metastasis \\
\hline 23 & $\mathrm{~F}$ & 67 & Malignant & Chondrosarcoma \\
\hline 24 & $\mathrm{~F}$ & 69 & Benign & Infection \\
\hline 25 & $\mathrm{~F}$ & 70 & Malignant & Multiple myeloma \\
\hline 26 & $\mathrm{M}$ & 70 & Malignant & Metastasis \\
\hline 27 & $M$ & 71 & Malignant & Multiple myeloma \\
\hline 28 & $\mathrm{~F}$ & 71 & Malignant & Lymphoma \\
\hline 29 & $\mathrm{~F}$ & 72 & Malignant & Plasmacytoma \\
\hline 30 & $\mathrm{M}$ & 77 & Malignant & Plasmacytoma \\
\hline 31 & $\mathrm{~F}$ & 84 & Malignant & Metastasis \\
\hline
\end{tabular}

illustrated in -Table 2. The most frequent benign tumor encountered within the study was osteochondromas $(n=3)$. Nonneoplastic lesions included total of four cases of osteomyelitis, fibrous dysplasia, and eosinophilic granuloma.

\section{Discussion}

\section{Anatomy}

The acromion is a large, flat bony anatomical structure that arises from the lateral end of the spine of the scapula and projects anteriorly to articulate with the lateral end of the clavicle. In the adult, it measures $\sim 2.5 \mathrm{~cm}$ in width and is roughly $5 \mathrm{~cm}$ long. It serves as an important landmark of the skeletal system, and provides muscle attachments for the deltoid and trapezius which are essential to the function of the shoulder joint. Lesions arising within the acromion have the potential to disrupt the shoulder complex, leading to severe morbidity due to loss of function.

\section{Chondrosarcoma}

Chondrosarcomas are malignant tumors that originate from cartilage producing cells (chondrocytes). They are known to be the second most common primary malignant osseous lesions, second to osteosarcoma. ${ }^{2}$ Chondrosarcoma of the scapula is relatively rare with a reported incidence of $\sim 5 \%{ }^{3}$ The incidence in the acromion is unknown. They typically arise between the fourth and fifth decades of life and have a slight male predilection. Clinically, chondrosarcomas have 
Table 2 Breakdown of type of acromial tumors

\begin{tabular}{|l|l|l|}
\hline Diagnosis & $\begin{array}{l}\text { Number of } \\
\text { patients }\end{array}$ & Percentage \\
\hline Chondrosarcoma & 7 & 23 \\
\hline Metastasis & 7 & 23 \\
\hline $\begin{array}{l}\text { Multiple myeloma or } \\
\text { plasmacytoma }\end{array}$ & 6 & 19 \\
\hline Lymphoma & 3 & 10 \\
\hline Osteochondroma & 2 & 6.4 \\
\hline Chondroblastoma & 2 & 6.4 \\
\hline Infection & 2 & 6.4 \\
\hline $\begin{array}{l}\text { Other benign lesions } \\
\text { 1. Fibrous dysplasia } \\
\text { 2. Eosinophilic granuloma }\end{array}$ & 2 & 6.4 \\
\hline
\end{tabular}

nonspecific symptoms often presenting with a painful palpable lump or local mass effect. ${ }^{4}$ Since clinical diagnosis is unreliable, patients suspected of having chondrosarcoma often undergo imaging.

On radiographs, chondrosarcomas demonstrate intralesional calcification, seen as ring-and-arc chondroid or popcorn-like calcification, with endosteal scalloping and soft tissue extension ( - Figs. 1,2,3). CT can also be useful to aid in delineating chondrosarcomas. On CT, chondrosarcoma appears with osteolytic destruction, endosteal scalloping, cortical breaching, calcification, and an expansile remodeling component (-Figs. 1,2,3). ${ }^{3}$

MRI is the gold standard imaging modality for radiological diagnosis. The nonmineralized portion of the lesion, the soft tissue mass, as well as the surrounding tissues can all be evaluated on MRI. The calcifications appear hypointense on all pulse sequences. The cartilaginous matrix manifests as lobulated high T2 and low T1 signal areas ${ }^{5}$ (-Figs. 1 and 2). It is important to note that when the thickness of the cartilage cap is more than $2 \mathrm{~cm}$ in mature bone, it is highly suggestive of malignant transformation from an original osteochondroma.

The radiological findings can reflect the pathological appearances of the different distinctive subtype features. High-grade chondrosarcomas are more likely to show variable MR appearance. The typical lobular appearance of the chondroid matrix is often absent in the dedifferentiated chondrosarcoma. Low-grade chondrosarcomas may have fibrovascular septa between lobules of hyaline cartilage and are more difficult to be distinguished from enchondromas. ${ }^{6}$ Therefore, an accurate diagnosis based on morphologic feature alone is difficult, and correlation of radiological and clinicopathological features is mandatory. ${ }^{7}$

\section{Metastasis-Breast and Renal Cell Carcinomas}

Skeletal metastasis is very common and considerably more prevalent than primary bone malignancy. ${ }^{8}$ The most common metastatic tumors identified within our cohort were secondary to breast and renal cell carcinoma primaries.

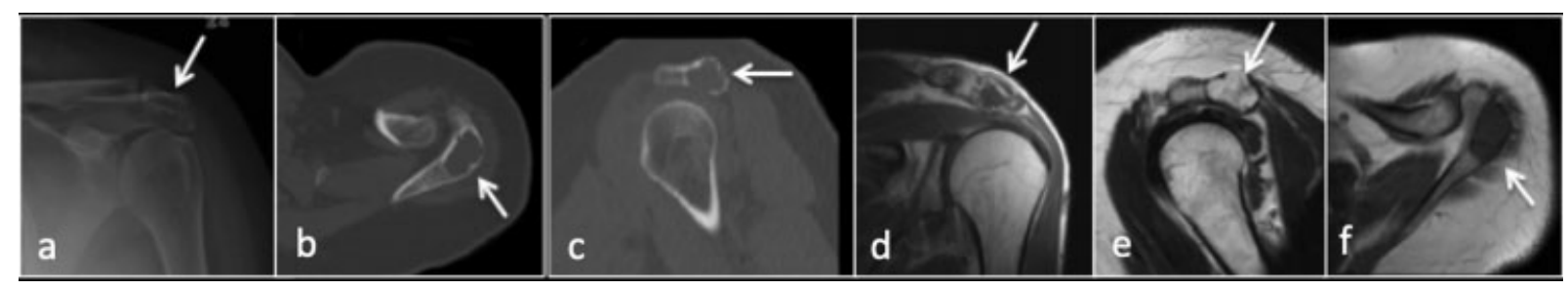

Fig. 1 Chondrosarcoma. Anteroposterior radiograph (a), computed tomography axial (b), sag (c), magnetic resonance imaging coronal T1 (d), sag T2 (e), and axial T1 (f) showing chondrosarcoma (arrow).

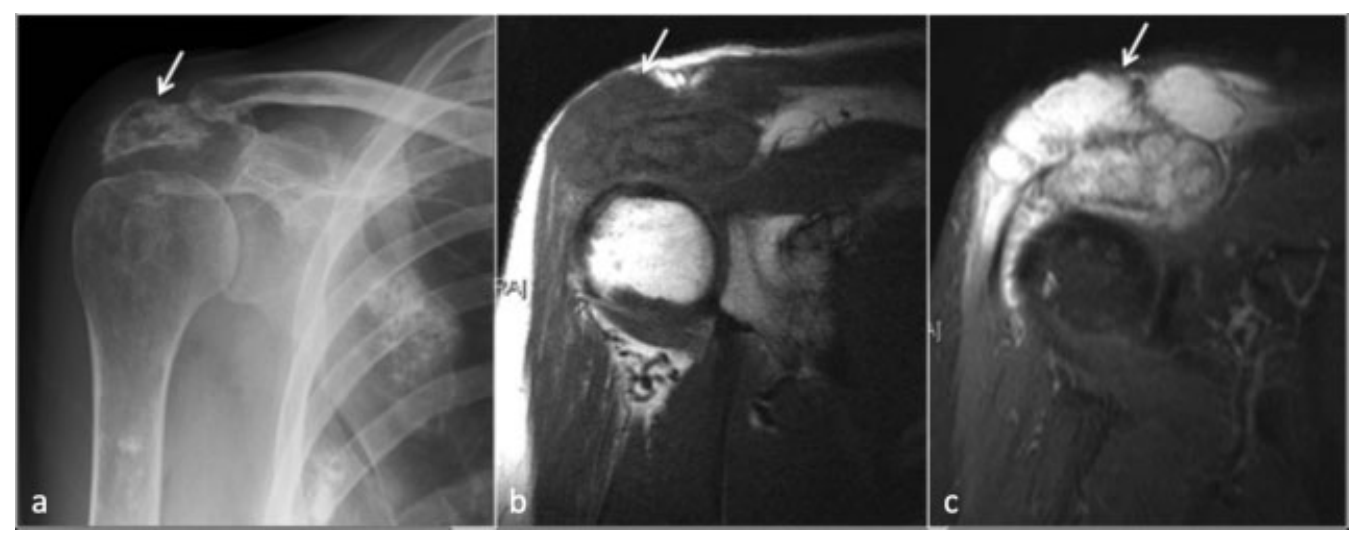

Fig. 2 Chondrosarcoma. Anteroposterior radiograph (a), magnetic resonance imaging coronal T1 (b), and short-tau inversion recovery coronal (c) chondrosarcoma (arrow). 


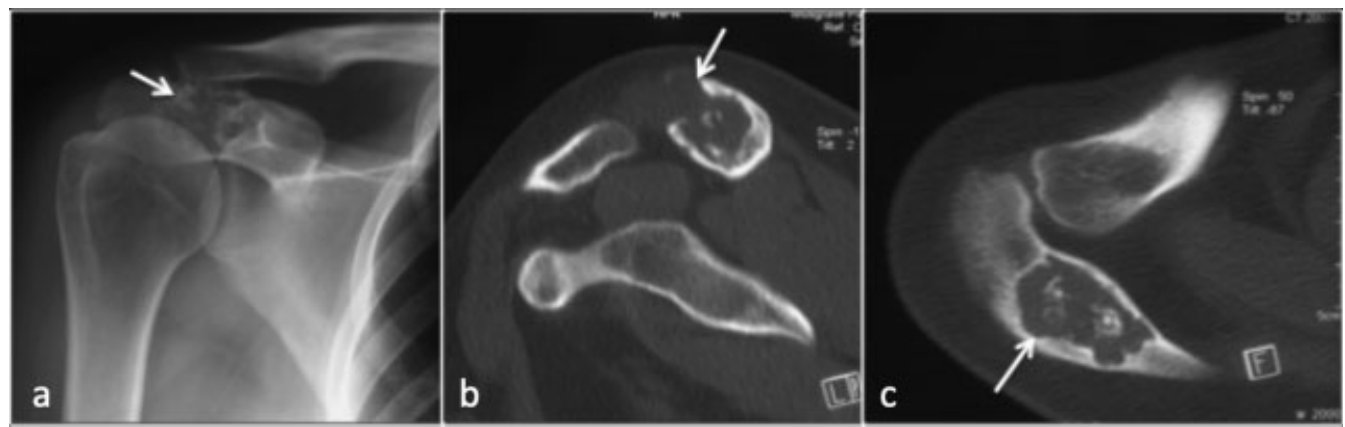

Fig. 3 Chondrosarcoma. Anteroposterior radiograph (a), computed tomography sag (b), and axial (c) showing chondrosarcoma (arrow).

Bone metastasis associated with breast and renal cancers is common, and thought to be due to the selective colonization of the tumor toward bone. ${ }^{9}$ History and clinical examination are key in ensuring appropriate diagnosis and management. Furthermore, imaging is essential to further confirm diagnosis and aid in management plans.

Radiographs are nonspecific and are mostly useful in the identification of associated pathological fractures. MRI is more conclusive, and features of metastatic breast carcinoma in the acromion process appear as destructive low signal intensity lesion on T1-weighted imaging (T1WI), with no significant fluid signal in the destructive lesion on T2weighted imaging (T2WI) (-Figs. 4,5,6).

In metastatic renal cell carcinoma, radiographs can demonstrate a more characteristic "soap bubble appearance," a poorly demarcated osteolytic lesion within the acromion process ( - Fig. 4). MRI is highly sensitive, due to its capability in demonstrating intramedullary metastatic deposits in the early stages of the disease. Signal voids can be seen in these as there is hypervascular metastasis (flow void sign). Moreover, it can be used to assess metastatic spread in the marrow cavity, the extension of tumor disease, and the involvement of other surrounding structures. Bony metastasis involving the scapula is generally treated nonsurgically with radiotherapy playing a critical role in the palliative management of these lesions. ${ }^{10}$

\section{Multiple Myeloma and Plasmacytoma}

Multiple myeloma (MM) is a plasma cell dyscrasia characterized by the abnormal proliferation of plasma cells and immunoglobulins in the blood that lead to specific end-organ

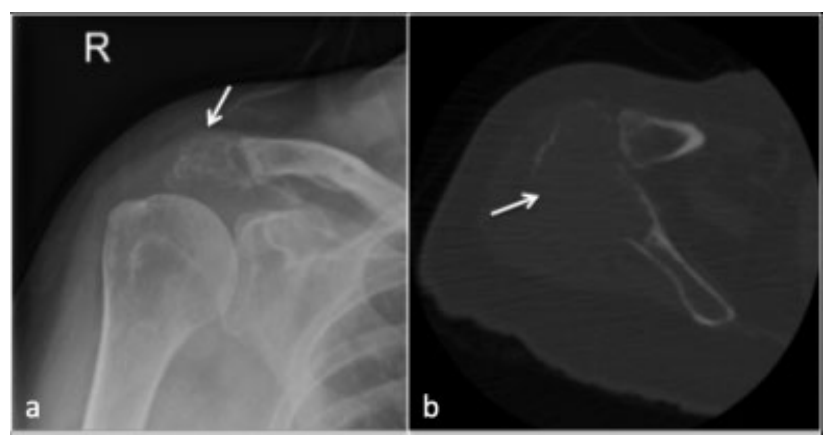

Fig. 4 Renal metastasis. Anteroposterior radiograph (a) and axial computed tomography (b) showing renal metastasis (arrow).

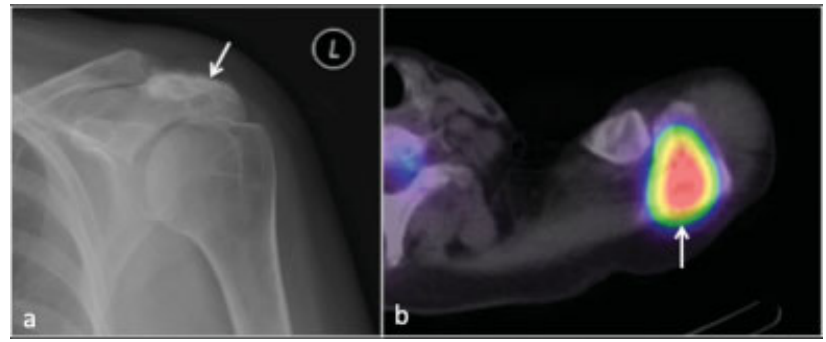

Fig. 5 Breast metastasis. Anteroposterior radiograph (a) and positron emission tomography-computed tomography (PET-CT) (b) showing left acromial metastasis with increased uptake on PET-CT (arrow).

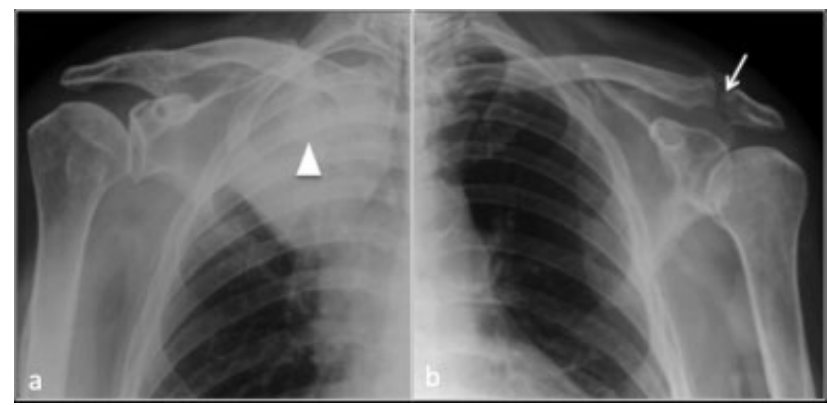

Fig. 6 Lung metastasis. Anteroposterior radiograph showing right bronchogenic carcinoma (arrow head) and left acromion metastasis (arrow).

damage. Plasmacytoma is the solitary localized variant of MM. ${ }^{11}$ Osseous manifestations of this tumor constitute a very important component of the disease. However, the incidence in the acromion process is not known, and as far as the authors are aware, it has not been reported in the literature.

Radiologically, four types of bone destruction can be caused by MM. ${ }^{12}$

- Type I: solitary plasmacytoma: a single expansile lesion, most common in vertebra and pelvis

- Type II: multiple "punched out" osteolytic lesion

- Type III: disseminated skeletal osteopenia causing diffuse osteoporosis

- Type IV: diffuse osteosclerosis.

The radiographic appearances of MM are nonspecific, and can present as a subtle lytic lesion in the acromion process (-Figs. 7 and 8 ). 


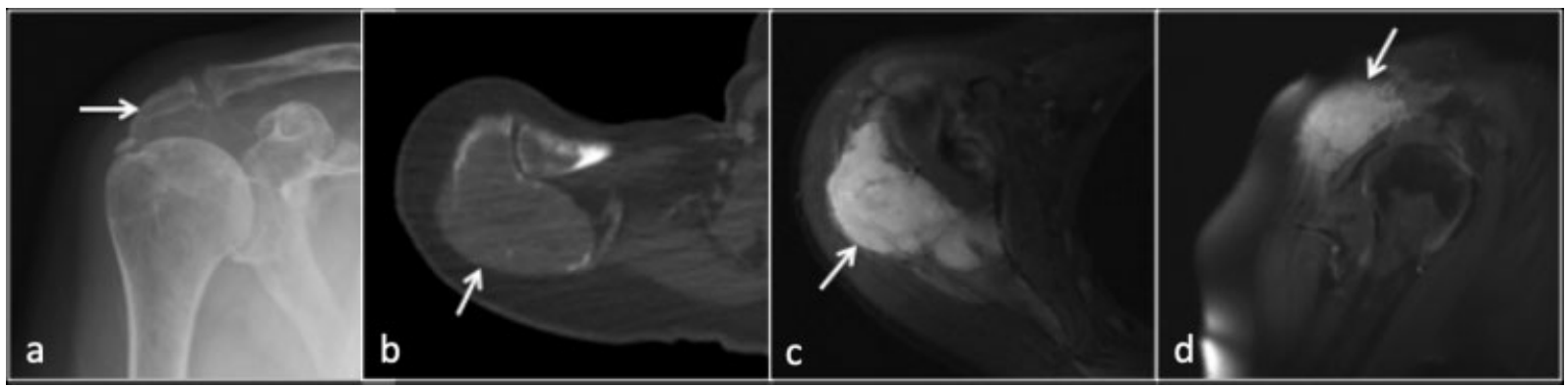

Fig. 7 Myeloma. Anteroposterior radiograph (a), magnetic resonance imaging (MRI) axial T1 (b), MRI axial short-tau inversion recovery (STIR) (c), and sag STIR (d) showing myeloma deposit (arrow).

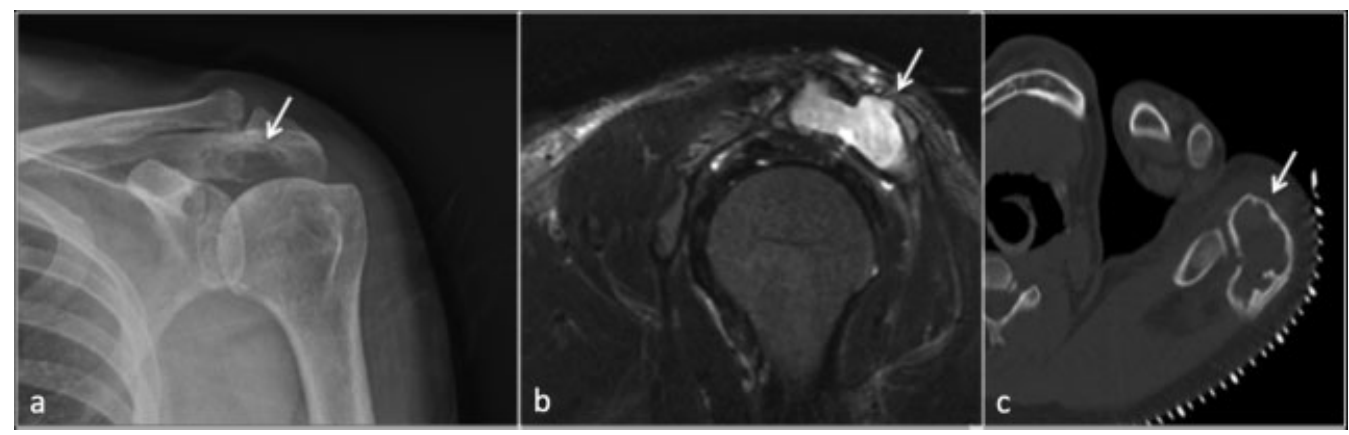

Fig. 8 Plasmacytoma. Anteroposterior radiograph (a), magnetic resonance imaging sag short-tau inversion recovery (b), and axial computed tomography (c) showing plasmacytoma (arrow).

On CT, features include a large expansile soft tissue mass with cortical breakthrough (-Fig. 7). CT imaging is also useful in evaluating pathological fracture risk and provides a platform to perform percutaneous imaging biopsy when required.

MRI is the imaging modality of choice when evaluating this lesion, and is highly sensitive and additionally plays a major diagnostic role in disseminated MM. On T1WI, MM appears as a homogenous isointense signal to the muscle. On $\mathrm{T} 2 \mathrm{WI}$, the lesion appears brighter than normal marrow signifying increased signal intensity. On fat-suppressed T1weighted sequences, the lesion has increased signal intensity (-Fig. 8). On gadolinium postcontrast sequence, myeloma deposits demonstrate contrast enhancement in acromion. On short-tau inversion recovery (STIR), the tumor appears to have high intensity signal. Treatment options vary and depend on stage and progression of disease. ${ }^{12}$ In plasmacytoma, localized radiotherapy is the preferred treatment of choice. In MM, the current recommended treatment is chemotherapy, and bone marrow or peripheral stem cell transplant along with other conservative measures.

\section{Non-Hodgkin's Lymphoma}

Primary osseous non-Hodgkin's lymphoma (NHL) is rare and accounts for 3 to $5 \%$ of all primary bone tumors. ${ }^{13} \mathrm{NHL}$ has many different subtypes, of which diffuse large B cell lymphoma or follicular lymphoma most commonly affects the bone. ${ }^{14}$

Radiographic features of osseous lymphoma are variable and depend on the subtype present. Often, extensive in- volvement of the bone with a "moth-eaten" destructive appearance is present and the periosteal reaction can show a "lamellated onion peel" or "discontinuous" appearance, associated with poor outcomes. ${ }^{15} \mathrm{CT}$ plays a role in the staging of the disease, ${ }^{16}$ while MRI is the mainstay imaging modality for the diagnosis of lymphoma.

On MRI, T1-weighted pulse sequences are optimal for demonstrating marrow changes, revealing areas of low signal intensity. On T2 images, the peritumoral area and reactive marrow changes generally appear bright. The soft tissue extension is usually disproportionately large in comparison to the cortical destruction (-Fig. 9). It has been suggested that this finding occurs due to the spread of the tumor cells from the bone marrow through small vascular channels that run through the cortex into the surrounding soft tissue. ${ }^{17}$ Despite imaging proving useful, a biopsy is almost always required to confirm the diagnosis. Treatment of NHL involves a mixture of chemotherapy and immunotherapy agents with aims to reduce the size of the lesion.

\section{Benign Lesions of the Acromion Process}

Benign lesions of the acromion process are rare and their incidence is not reported in the literature. Benign tumors of the acromion identified within our cohort included osteochondromas and chondroblastoma.

\section{Osteochondroma}

Osteochondroma is the most common benign bone tumor. It is commonly found in adolescents and children. ${ }^{18}$ They can 


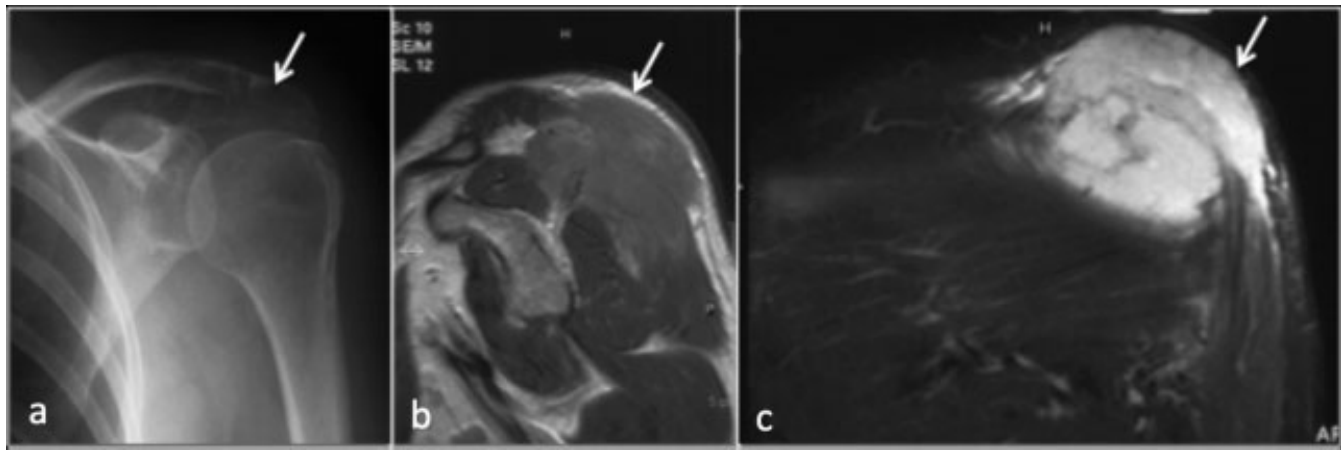

Fig. 9 Lymphoma. Anteroposterior radiograph (a) magnetic resonance imaging T1 sag (b), and coronal short-tau inversion recovery (c) showing lymphoma involving the acromion (arrow).

be solitary or multiple, the latter often associated with hereditary multiple exostoses syndrome. Osteochondroma of the scapula is found in $\sim 3$ to $5 \%$ of all osteochondroma cases. ${ }^{19}$ Their incidence in the acromion is unknown, with limited reported cases in the literature. ${ }^{20-22}$ Osteochondromas of the acromion can either present with a noticeable or asymptomatic mass, signs of impingement syndrome, ${ }^{20,21}$ or with secondary complications caused by the tumor including fractures, bony deformity, vascular compromise, neurological sequelae, or bursa formation. ${ }^{23}$ It is important to note that osteochondromas do also have a potential for malignant transformation. ${ }^{23,24}$

Both radiographs and CT images of osteochondroma may demonstrate a sessile or pedunculated lesion with cortical irregularity, medullary continuity, and a cartilage cap.

MRI is the gold standard imaging modality used to assess the cartilage cap ( $\mathbf{- F i g . 1 0}$ ). Postcontrast MRI may demonstrate the heterogenous enhancement in the lesion. Treatment options are individualized to patient's preference, with asymptomatic or minimally symptomatic lesions often undergo surveillance and provided with supportive care. Surgical resection can be considered if there is a risk of an impending fracture or the presence of the other secondary complications described earlier.

\section{Chondroblastoma}

Chondroblastoma is a rare benign but aggressive cartilaginous neoplasm formed of chondroblasts. ${ }^{25}$ Chondroblastomas are rare and represent less than 1 to $2 \%$ of all primary bone tumors. It usually affects adolescents and young adults, with a slight male predominance. The acromion is a very rare site for this tumor to arise with only a few cases reported in the literature. ${ }^{26}$ Chondroblastomas are best demonstrated on MRI appearing as a low to intermediate signal intensity homogenous lesion on T1WI. On T2WI, the lesion demonstrates intermediate to high signal intensity. Moreover, secondary aneurysmal bone cysts can be seen accompanying chondroblastomas in $\sim 20 \%$ of cases, classically presenting with the fluid-fluid levels. ${ }^{27}$ On radiographs and CT images, chondroblastomas are characteristically seen as single lucent lesions, with either smooth or lobulated margins, septations, cortical expansion, or a sclerotic rim. CT is particularly useful to define the relationship of the tumor with the surrounding tissues given the destructive nature of the tumor. Management of chondroblastoma includes curettage, marginal resection, and percutaneous radiofrequency ablation.

\section{Osteomyelitis}

Other lesions we identified within our cohort included infection. These lesions can be distinguished with appropriate clinical history and examination. Patients with osteomyelitis or eosinophilic granuloma of the acromion can present with debilitating symptoms such as pain, sepsis, and loss of function. ${ }^{28}$ Therefore, early diagnosis and management are essential to ensure effective treatment is initiated.

Nonneoplastic lesions can have similar imaging features to that of tumors. Radiographic imaging is usually first line,

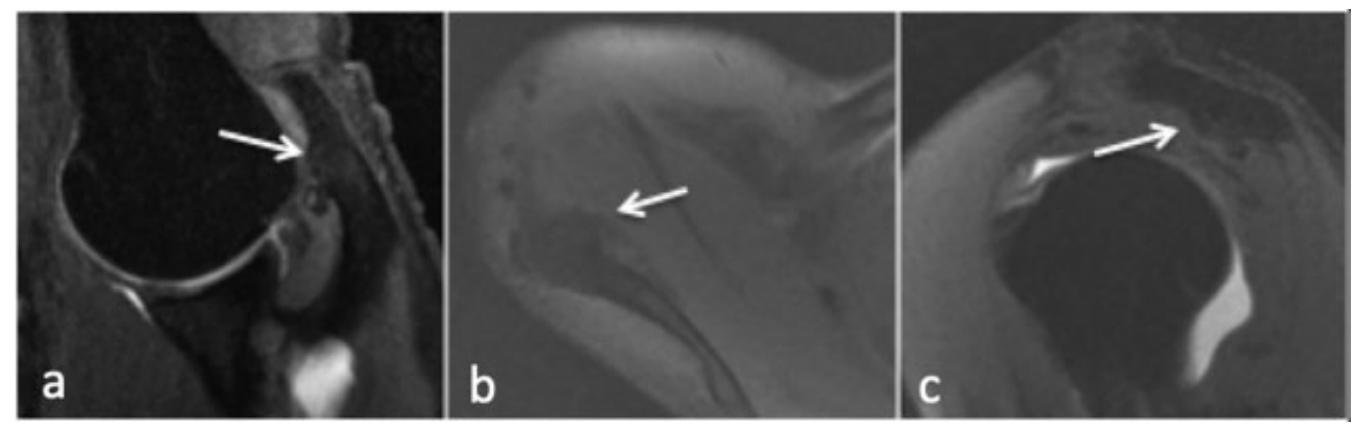

Fig. 10 Osteochondroma. Magnetic resonance imaging short-tau inversion recovery (STIR) axial (a, b) and sag STIR (c) showing osteochondroma (arrow). 


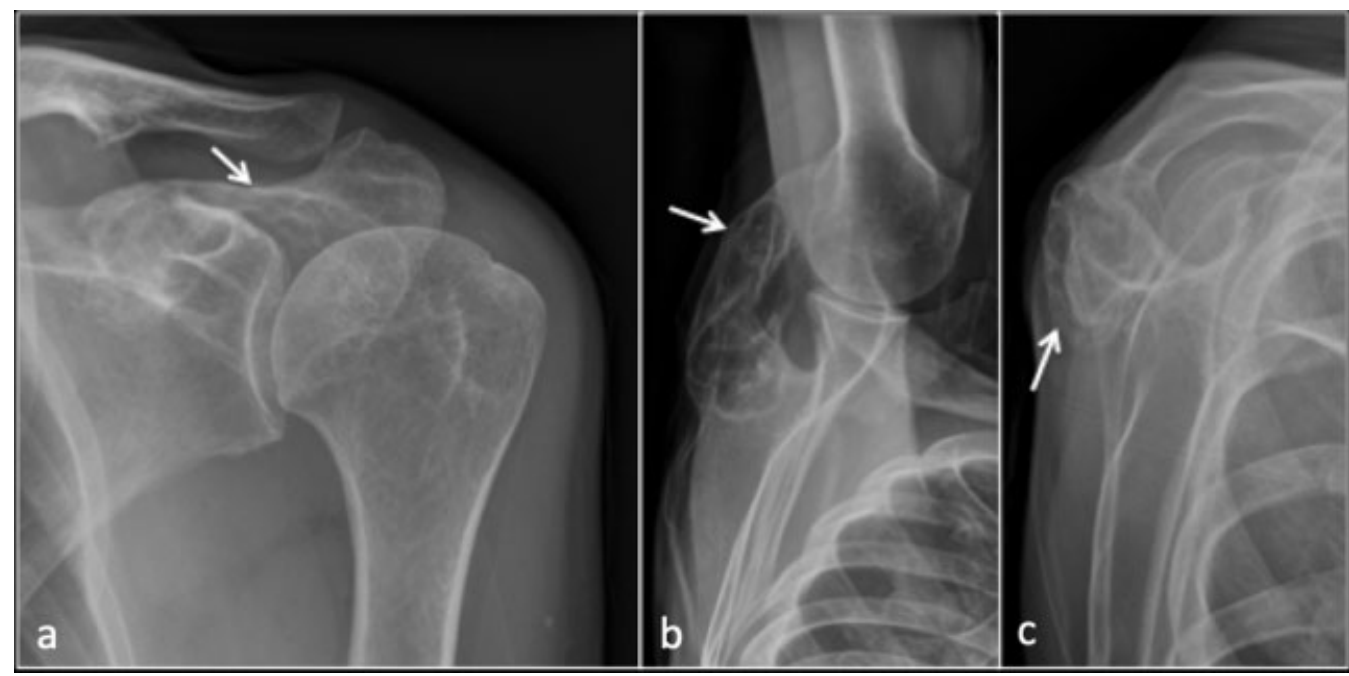

Fig. 11 Fibrous dysplasia. Anteroposterior radiograph (a), axial (b), and Y view (c) showing fibrous dysplasia (arrow).

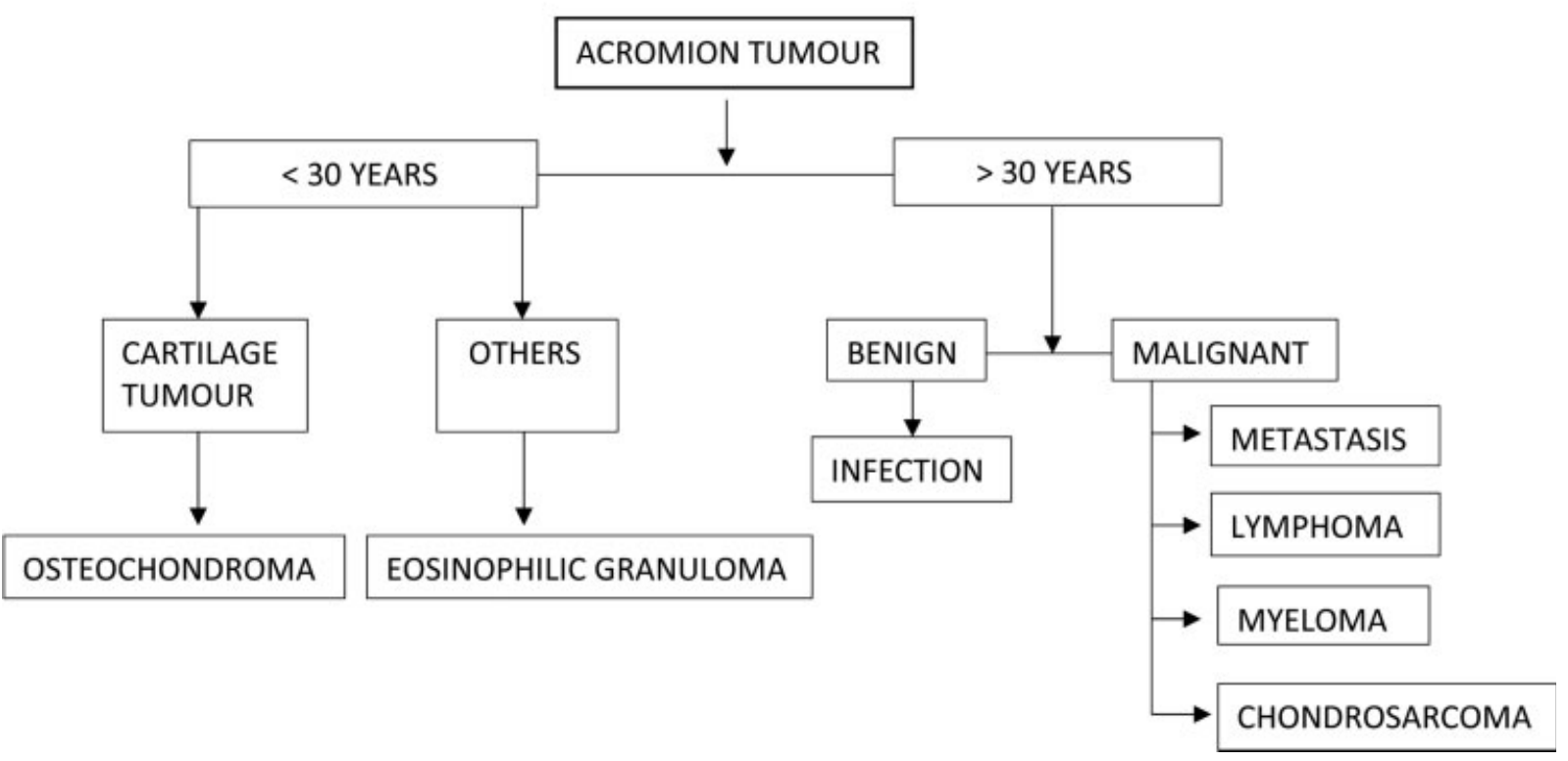

Fig. 12 Diagnostic algorithm of acromion tumors.

but has a low sensitivity and specificity for detecting infection of the bone. ${ }^{29}$ However, it is necessary to exclude other pathologies such as fractures. Late signs (7-10 days) that can be seen on radiographs include destruction of the bone typically manifesting as a focal radiolucent lesion. MRI is the predominant imaging modality for diagnosis of infection, owing to its high sensitivity for detecting edema around the focus of infection. T2-weighted and STIR images may demonstrate high signal intensity in the acromion, subperiosteal fluid, and subacromial bursa fluid. CT may be helpful if a sequestrum is suspected on MRI.

Other lesions of acromion include eosinophilic granuloma and fibrous dysplasia (-Fig. 11).

\section{Conclusion}

Tumors of the acromion are rare. We provide the largest case series of lesions of the acromion and present a comprehensive pictorial review and diagnostic algorithm aimed at aiding radiologists in the diagnosis of these lesions (-Fig. 12). Majority of acromion tumors are malignant.

\section{Funding}

None.

Conflict of Interest

None declared. 


\section{References}

1 Young J. Bone tumors: general aspects and data on 8,547 cases. 4th ed. Radiology 1987;164(02):424-424

2 Pant R, Yasko AW, Lewis VO, Raymond K, Lin PP. Chondrosarcoma of the scapula: long-term oncologic outcome. Cancer 2005;104 (01):149-158

3 Qiang S, Ma XN, Wang HW, Lv SC. Scapula chondrosarcoma: a case report. Medicine (Baltimore) 2019;98(17):e15388

4 Pescador D, Blanco J, Corchado C, et al. Chondrosarcoma of the scapula secondary to radiodermatitis. Int J Surg Case Rep 2012;3 (04):134-136

5 Blacksin MF, Benevenia J. Neoplasms of the scapula. AJR Am J Roentgenol 2000;174(06):1729-1735

6 Geirnaerdt MJ, Hogendoorn PC, Bloem JL, Taminiau AH, van der Woude HJ. Cartilaginous tumors: fast contrast-enhanced MR imaging. Radiology 2000;214(02):539-546

7 Kim MJ, Cho KJ, Ayala AG, Ro JY. Chondrosarcoma: with updates on molecular genetics. Sarcoma 2011;2011:405437

8 Bussard KM, Gay CV, Mastro AM. The bone microenvironment in metastasis; what is special about bone? Cancer Metastasis Rev 2008;27(01):41-55

9 Chen SC, Kuo PL. Bone metastasis from renal cell carcinoma. Int J Mol Sci 2016;17(06):987

10 Grünwald V, Eberhardt B, Bex A, et al. An interdisciplinary consensus on the management of bone metastases from renal cell carcinoma. Nat Rev Urol 2018;15(08):511-521

11 NORD (National Organization for Rare Disorders) (2019). Multiple Myeloma - NORD (National Organization for Rare Disorders). [online]. Accessed July 4, 2019 at: https://rarediseases.org/rare-diseases/multiple-myeloma/

12 Ghosh S, Wadhwa P, Kumar A, Pai K, Seshadri S, Manohar C. Abnormal radiological features in a multiple myeloma patient: a case report and radiological review of myelomas. Dentomaxillofac Radiol 2011;40(08):513-518

13 Barbieri E, Cammelli S, Mauro F, et al. Primary non-Hodgkin's lymphoma of the bone: treatment and analysis of prognostic factors for stage I and stage II. Int J Radiat Oncol Biol Phys 2004;59 (03):760-764

14 Chua SC, Rozalli FI, O'Connor SR. Imaging features of primary extranodal lymphomas. Clin Radiol 2009;64(06):574-588
15 Krishnan A, Shirkhoda A, Tehranzadeh J, Armin AR, Irwin R, Les K. Primary bone lymphoma: radiographic-MR imaging correlation. Radiographics 2003;23(06):1371-1383, discussion 1384-1387

16 Kwee TC, Kwee RM, Nievelstein RA. Imaging in staging of malignant lymphoma: a systematic review. Blood 2008;111(02):504-516

17 Hicks DG, Gokan T, O'Keefe RJ, et al. Primary lymphoma of bone. Correlation of magnetic resonance imaging features with cytokine production by tumor cells. Cancer 1995;75(04):973-980

18 Murphey MD, Choi JJ, Kransdorf MJ, Flemming DJ, Gannon FH. Imaging of osteochondroma: variants and complications with radiologic-pathologic correlation. Radiographics 2000;20(05):1407-1434

19 Cooley LH, Torg JS. "Pseudowinging" of the scapula secondary to subscapular osteochondroma. Clin Orthop Relat Res 1982;(162): 119-124

20 Çıtlak A, Akgün U, Bulut T, Aslan C, Mete BD, Şener M. Subacromial osteochondroma: a rare cause of impingement syndrome. Int J Surg Case Rep 2015;6C:126-128

21 Craig EV. Subacromial impingement syndrome in hereditary multiple exostoses. Clin Orthop Relat Res 1986;(209):182-184

22 Frost NL, Parada SA, Manoso MW, Arrington E, Benfanti P. Scapular osteochondromas treated with surgical excision. Orthopedics 2010;33(11):804

23 Vallance R, Hamblen DL, Kelly IG. Vascular complications of osteochondroma. Clin Radiol 1985;36(06):639-642

24 Mohsen MS, Moosa NK, Kumar P. Osteochondroma of the scapula associated with winging and large bursa formation. Med Princ Pract 2006;15(05):387-390

25 Lin PP, Thenappan A, Deavers MT, Lewis VO, Yasko AW. Treatment and prognosis of chondroblastoma. Clin Orthop Relat Res 2005; 438(438):103-109

26 Arıkan M, Toğral G, Yıldırım A, Irkkan Ç A rare case of chondroblastoma of the acromion. Acta Orthop Traumatol Turc 2016;50 (06):691-693

27 Nithin S, Puttaswamy P. Benign chondroblastoma with secondary aneurysmal bone cyst in scapula. OA Orthopaedics 2013;1(02):18

28 Kendall J, McNally M. Septic arthritis of the shoulder with proximal humerus osteomyelitis, treated by Ilizarov shoulder arthrodesis. J Bone Jt Infect 2017;2(02):90-95

29 Lee YJ, Sadigh S, Mankad K, Kapse N, Rajeswaran G. The imaging of osteomyelitis. Quant Imaging Med Surg 2016;6(02):184-198 